\title{
The Incidence And Severity Of Frey's Syndrome After Parotidectomy: A Retrospective Study
}

\author{
Mustafa Daloglu1', Kenan Guney² \\ 1 M.D. , MSc., Department of Medical Education, Akdeniz University School of Medicine, Antalya, Turkey \\ ORCID: 0000-0002-6315-4897
}

2 Professor, M.D., Department of Otolaryngology, Head and Neck Surgery, Akdeniz University School of Medicine, Antalya, Turkey ORCID: 0000-0001-7688-3805

\begin{abstract}
Objective: The aim of this study was to investigate the incidence and severity of Frey's syndrome (FS) among parotidectomy patients and to assess the impact of parotidectomy sequelae on quality of life (QoL).
\end{abstract}

Methods: In total, 43 patients (21 males, 22 females) who underwent parotidectomy were included in this study. lodine-starch test was applied to identify the presence and the severity of FS. The results were evaluated using a previously described grading system. Patients' perceptions of parotidectomy sequelae were graded to identify their impact on QoL and also if there is an association between the extent of parotidectomy, the time elapsed after surgery and the severity of symptoms.

Results: FS was diagnosed in $18(41.8 \%)$ patients, 10 of which $(23.3 \%)$ reported having FS symptoms. Of all patients who were diagnosed with FS, 11 (61.2\%) patients' symptoms were classified as mild, whereas 7 (38.8\%) were classified as severe. There was no significant correlation between the incidence of FS and the time between surgery and diagnosis, or the extent of parotidectomy. Among all symptoms reported by patients, FS was the sequelae that caused the most discomfort after parotidectomy.

Conclusion: The negative impact of FS on QoL is restricted to cases with severe symptoms, the incidence of which is rare and independent of the extent of surgery. To avoid overtreatment, true incidence of FS remains to be identified in study samples from different centers. By this means, clinicians can make more accurate definitions for indications of preventive procedures as well as treatment approaches.

Keywords: Frey's syndrome, parotidectomy, quality of life
Correspondence: Dr. Mustafa Daloğlu

Pinarbasi Mah. 743. Sokak 8/8 07070 Konyaalti ANTALYA/TURKEY

e-mail: drmustafadaloglu@gmail.com

Received: 20.05.2019; Accepted: 25.06.2019
Online available at: www.entupdates.org

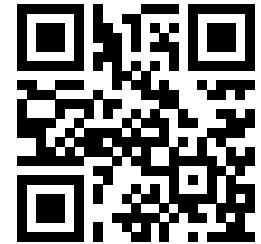




\section{Introduction}

Gustatory sweating was first described by Duphenix (1757) and Baillarger (1853) in patients with inflammatory parotid gland disease. In 1923, the Polish neurologist Lucja Frey described this condition as a new syndrome characterized by localized cervico-facial hyperhidrosis and erythema during mastication. It can develop following a variety of conditions but is most commonly encountered as a complication of parotidectomy which is a common surgical procedure performed for a wide array of tumours and inflammatory diseases. ${ }^{[1]}$

The underlying mechanism of this condition now termed as Frey's Syndrome (FS) is well documented and commonly reported to be an outcome of misdirected nervous regeneration. ${ }^{[2,3]}$ During parotidectomy, the postganglionic parasympathetic fibers of the auriculotemporal nerve, which innervate the parotid gland, are inevitably sectioned resulting in regeneration and anastomosis of these fibers to the excised distal ends of the sympathetic nerves that innervate the subcutaneous sweat glands. ${ }^{[4]}$ Consequently, the patient suffers from gustatory sweating and flushing on the parotid region during mastication. The re-innervation process requires certain amount of time, which results in a delayed onset of symptoms following the operation. In most cases, FS occurs with a latency period of 6-18 months or more postoperatively. ${ }^{[5]}$

The diagnosis of FS can readily be achieved using the iodine-starch test initially described by Minor, which still remains as the standard approach to eliminate other differential diagnoses. ${ }^{[6]}$ Although reported to be a safe and effective method, a limitation of this test is the potential effect of the room temperature on sweating. False positive results may occur in conditions when a negative control is not utilized in warm temperatures. However, when applied for the right indication and adhering to previously described principles, the iodine-starch test remains as a reliable method in the diagnosis of FS.

A current review of the literature fails to identify the true incidence of FS after parotid surgery, which is reported to vary considerably ranging from 5 to $100 \%$ among different centers and researchers. ${ }^{[7-9]}$ Despite the high incidence of FS reaching up to $100 \%$, no criteria have been consistently reported to effectively assess the incidence and severity this condition. Only a few studies have previously described the use of grading systems to determine the severity of FS and thereby objectively indicate conditions, which require treatment. ${ }^{[10]}$
Other common sequelae after parotidectomy include scar formation of the incision site, depression of the parotidectomy bed, facial motor weakness, dysesthesia around the ear lobe, and decreased salivation. When combined with the symptoms of FS, these conditions may further diminish the quality of life among affected patients.

The aim of this study was to evaluate the incidence and severity of FS after parotidectomy, and to determine its impact on quality of life with respect to commonly reported sequelae. The correlation of the extent of the parotid surgery and the time elapsed after the operation with the onset and the severity of symptoms was also assessed to evaluate the need for the treatment of FS.

\section{Materials and Methods}

\section{Subjects:}

In total, 98 patients who underwent parotidectomy between 2010 and 2013 at the Akdeniz University Hospital Department of Otolaryngology - Head and Neck Surgery were invited to complete the iodine-starch test. Patients who consented to be tested $(n=43)$ were included in this retrospective study. The pathological diagnosis and type of parotid surgery, chemotherapy, or radiotherapy treatment were not considered as exclusion criteria.

Minor's test: The presence of gustatory sweating was assessed and Minor's test was performed in all patients. Female patients were asked to remove their makeup and males were asked to shave. An iodine solution (1.5 g iodine, $10 \mathrm{~g}$ castor oil, and $125 \mathrm{~mL}$ 95\% ethanol) was applied to the skin surface of the pre-auricular, post-auricular, and parotid bed regions as well as the ear lobe. The solution was left to dry for 5 minutes and a starch powder was subsequently applied. All tests were performed bilaterally to avoid false positive results. The affected area was observed and recorded in $\mathrm{cm}^{2}$. The patients were examined for scar formation, depression of the parotidectomy bed, and facial motor weakness. Dysesthesia around the ear lobe and decreased salivation were also assessed and patients were asked about any discomfort experienced due to sequelae. To determine the most uncomfortable sequelae a questionnaire was designed on which patients were asked to score their self-perceptions of the sequelae on a scale ranging from 0 (extreme discomfort) to 10 (no complaints). The scores assigned to FS were divided into three subgroups. Scores ranging from 0 to 5 were considered severe and those 
ranging from 6 to 9 were considered mild. Patients with scores of 10 were considered to have no discomfort.

Grading system: A grading system described by LunaOrtiz et al. was also used to define the severity of FS using the following four criteria: (1) the presence of any clinical manifestations perceived by the patient, (2) extension of the positive skin area according to Minor's test, (3) excessive sweating that disturbs the patient (can also be present without affecting the patient's quality of life), and (4) unpleasant smelling sweat without any cause other than FS. ${ }^{[1]}$ The values assigned to each criterion are shown in Table 1. Patients with 3 points or less were classified as having mild FS and patients with 4 points or higher were classified as having severe FS.

Statistical analysis: Data analysis was performed using the Statistical Package for Social Sciences version 22.0 (Armonk, NY, IBM Corp). Numerical variables are presented as mean \pm standard deviation and categorical variables are presented as percentages by descriptive statistics. The Chisquared test was used to compare differences in categorical variables between the groups. The Pearson chi-squared test or Fisher's exact test were used to compare categorical variables. Statistical significance was considered at probability value of $\leq 0.05$.

\section{Results}

In total, 43 patients were included in this study ( 21 males, $48.8 \%$; 22 females, $51.2 \%$ ). The mean age was $49.2 \pm 13.9$ years (range: $17-76$ years). The types of surgery performed were superficial parotidectomy and total parotidectomy in $36(83.7 \%)$ and $7(16.3 \%)$ cases, respectively.

FS was confirmed in 18 patients (41.9\%) using Minor's test. Of these, only $10(55.5 \%)$ were aware of the condition. The affected skin surface area was $0-2 \mathrm{~cm}^{2}$ in nine patients $(50 \%), 2-4 \mathrm{~cm}^{2}$ in five patients $(27.7 \%)$, and $>4 \mathrm{~cm}^{2}$ in four patients (22.3\%). Excessive focal sweating was found in four patients (22.3\%) and an unpleasant smell was described only by three patients (16.6\%). According to the grading system suggested by Luna-Ortiz et al ${ }^{[1]}$, seven patients $(38.8 \%)$ had severe FS and eleven patients $(61.2 \%)$ had mild FS (Table 1$)$; the mean total score was $3.44 \pm 2.59$. No significant associations were found between the type of surgery $(p=0.437)$ or treatment with adjuvant radiotherapy $(p=0.243)$ and the development of FS. The impact of scar formation, depression of the parotidectomy bed, facial motor weakness, dysesthesia around the ear lobe, salivation on the development of FS was investigated, but no correlation was found.

\begin{tabular}{|c|c|c|}
\hline & Value & Results (n / \%) \\
\hline \multicolumn{3}{|c|}{ Presence of clinical manifestations } \\
\hline Yes & 1 & $10 / 55.5 \%$ \\
\hline No & 0 & $8 / 44.5 \%$ \\
\hline \multicolumn{3}{|l|}{ Extent of the affected area } \\
\hline $0.1-2.0 \mathrm{~cm}^{2}$ & 1 & $9 / 50 \%$ \\
\hline $2.1-4.0 \mathrm{~cm}^{2}$ & 2 & $5 / 27.7 \%$ \\
\hline$>4.0 \mathrm{~cm}^{2}$ & 3 & $4 / 22.3 \%$ \\
\hline Excessive focal sweating & 3 & $4 / 22.3 \%$ \\
\hline Unpleasant smell of sweat & 3 & $3 / 16.6 \%$ \\
\hline Mild Frey's syndrome & $1-3$ points & $11 / 61.2 \%$ \\
\hline Severe Frey's syndrome & $\geq 4$ & $7 / 38.8 \%$ \\
\hline
\end{tabular}

The time elapsed from surgery to diagnosis was 1 year in two patients, 2 years in four patients, 3 years in six patients, and more than 3 years in six patients. While there was a trend for an increase in the incidence of FS with elapsed time from surgery to diagnosis, it was not significant $(p=0.455)$ (Table 2).

The impact of other complications on quality of life is shown in Table 3. According to the mean questionnaire scores, FS was the most uncomfortable sequelae, followed by depression of the parotidectomy bed and dysesthesia around the ear lobe. The lowest minimum scores were assigned to FS and facial motor weakness.

The distribution of scores for the questionnaire assessing quality of life of patients with FS is shown in Table 4. According to the self-perception scores, six patients (13.9\%) obtained 5 points or less and were classified as having severe FS, while the number of patients with mild FS was four $(9.3 \%)$. These patients were the same 10 patients 
Table 2. Distribution of patients by elapsed time from surgery to diagnosis.

\begin{tabular}{|c|c|c|c|c|c|}
\hline \multirow{2}{*}{ Postoperative time } & \multicolumn{2}{|c|}{ Frey's syndrome patients $(n=18)$} & \multicolumn{2}{|c|}{ All patients $(n=43)$} & \multirow{2}{*}{$\begin{array}{c}\text { Incidence } \\
\%\end{array}$} \\
\hline & $\mathrm{n}$ & $\%$ & $n$ & $\%$ & \\
\hline $0-1$ years & 2 & $11.1 \%$ & 7 & $16.3 \%$ & $28.6 \%$ \\
\hline $1-2$ years & 4 & $22.2 \%$ & 13 & $30.2 \%$ & $30.8 \%$ \\
\hline $2-3$ years & 6 & $33.3 \%$ & 13 & $30.2 \%$ & $46.2 \%$ \\
\hline$>3$ years & 6 & $33.3 \%$ & 10 & $23.3 \%$ & $60 \%$ \\
\hline
\end{tabular}

Table 3. Patient complications and overall and minimum quality of life scores.

\begin{tabular}{|c|c|c|c|c|}
\hline & Positive cases $\mathrm{n} / \%$ & Negative cases $\mathrm{n} / \%$ & Scores mean \pm SD & Minimum score \\
\hline Scar formation & $2 / 4.7$ & $41 / 95.3$ & $9.51 \pm 0.82$ & 6 \\
\hline Depression of PB & $28 / 65.1$ & $15 / 34.9$ & $9.0 \pm 0.87$ & 7 \\
\hline Facial motor weakness & $2 / 4.7$ & $41 / 95.3$ & $9.65 \pm 1.60$ & 2 \\
\hline Dysesthesia around the ear lobe & $27 / 62.8$ & $16 / 37.2$ & $9.16 \pm 0.78$ & 7 \\
\hline Decreased salivation & $7 / 16.3$ & $36 / 83.7$ & $9.67 \pm 0.80$ & 7 \\
\hline Frey's syndrome & $18 / 41.9$ & $25 / 58.1$ & $8.83 \pm 2.34$ & 1 \\
\hline
\end{tabular}

SD, standard deviation; PB, parotid bed.

who had clinical manifestations according to the grading system of Luna-Ortiz et al. ${ }^{[1]}$ The results from our quality of life questionnaire, and those from the scale by Luna-Ortiz et al ${ }^{[11]}$, were $70 \%$ consistent with respect to determining the severity of FS. The classification was different between the two measures in three patients.

\section{Discussion}

Frey's syndrome is a common complication of parotid surgery, the incidence of which remains an issue of debate. It is reported to be highly variable in the literature (5-100\%) ${ }^{[10]}$; although the mean worldwide incidence is commonly reported in about $66 \%$ of all cases. ${ }^{[12-14]}$ This variation depends on factors such as the study design, the use of preventive surgical treatments, and the criteria used for diagnosis. ${ }^{[5]}$ Therefore, it was among the efforts of this study to determine the incidence of FS in a group of patients

\begin{tabular}{|c|c|c|c|}
\hline Score & Patients (n) & Percent (\%) & Severity \\
\hline 1 & 1 & 2.3 & \\
\hline 3 & 1 & 2.3 & \\
\hline 4 & 2 & 4.7 & Severe \\
\hline 5 & 2 & 4.7 & \\
\hline 6 & 1 & 2.3 & \\
\hline 7 & 2 & 4.7 & Mild \\
\hline 8 & 1 & 2.3 & \\
\hline 10 & 33 & 76.7 & No complaints \\
\hline Total & 43 & 100 & \\
\hline
\end{tabular}


did not undergo intraoperative preventive surgical measures.

Among other diagnostic options, Minor's iodine-starch test remains a valuable and reliable alternative for the diagnosis of FS. In this study, Minor's test was utilized for diagnosis as it can not only detect gustatory sweating in symptomatic patients but also in the ones that are unaware of the condition. ${ }^{[15]}$

In our study, no patient was treated with preventive surgical measures and the incidence of FS was found to be $41.9 \%$, which is lower than the estimated worldwide incidence after parotidectomy procedures. Current evidence in the literature fails to offer adequate information on the incidence of FS and the role of preventive measures in avoiding clinical symptoms. Although several studies have demonstrated that approximately $60 \%$ of patients, who had undergone parotidectomy did not develop FS without preventive surgical procedures, many authors have pointed out that these procedures are associated with a decreased clinical FS onset. ${ }^{[16-20]}$ On the other hand, there are recent studies that fail to identify lower risk of FS development despite application of preventive measures. ${ }^{[14,21]}$ Grosheva et al. performed sternocleidomastoid muscle flap (SCMMF) interpositioning after superficial parotidectomy and they observed highly prevalent FS symptoms following surgery. [21] Wille-Bischofberger et al reported that superficial muscular aponeurotic system (SMAS) flap delays the onset in parotid surgery for benign lesions, and reduces the intensity and the extent of symptoms but does not effectively prevent development of FS. ${ }^{[2]}$ These findings are later confirmed by Lafont et al. who also performed SMAS flap reconstruction and reported no additional benefit on preventing FS development. ${ }^{[13]}$ Because of these controversial outcomes, no additional preventive surgical approach is routinely being undertaken following parotidectomy procedures at the institution, where the present study was carried out.

It is noteworthy that additional procedures to avoid FS development have certain limitations and are associated with several complications. Injury of the spinal accessory nerve is a previously reported complication of SCMMF interpositioning. ${ }^{[23]}$ Temporoparietal fascia flap is another recommended approach to decrease the incidence of FS, although it is also associated with various complications including facial nerve paralysis, hematoma formation and cosmetic complications such as alopecia and extensive scar formation in the temporal region. ${ }^{[24,25]}$ The use of SMAS flaps on the other hand are limited to benign parotid diseases, due to its anatomic relation to the parotid gland. [26,27] The authors of this study, therefore, believe that determining the exact incidence of FS is of significant importance in order to avoid overtreatment.

In this study, $16 \%$ of the patients were classified as having severe FS, who were later recommended to receive medical treatment. This finding is particularly significant as the patient awareness of symptoms among diagnosed cases was only $55 \%$, while the rest of the patients had only minor symptoms and were not aware of their conditions. When the findings of above-mentioned studies are taken into consideration, it can be concluded that performing preventive surgical procedures in all our patients would have resulted in overtreatment of $84 \%$ of the patients, and therefore introduced additional risks of complications. The authors of this study however, believe that if predictor variables are clearly defined for FS development after parotidectomy procedures, these may be used effectively to help clinicians better identify indications of preventive measures. To serve this purpose, Lee et al recently suggested using parotid tumor size as a predictor of FS development [28], although such an effort was not made in the present study due to limitations inherent to retrospective nature of this investigation.

According to the scale developed by Luna-Ortiz et al, $38.8 \%$ ( $n=7$ ) of patients had severe FS, while in the original study by the same group of authors, the rate of severe FS was $57.1 \%{ }^{[10]}$ The difference between the findings of this study and the present study can be attributed to shorter follow-up periods that were used in this investigation. In this study, two of the patients with severe FS symptoms presented during the third year and fourth year following surgery while no patient reported having severe symptoms related to FS within the postoperative first year. Thus, our findings indicate that the time elapsed after surgery may affect not only the incidence of this syndrome, but also its severity. The correlation between postoperative duration after surgery and FS incidence was not found to be statistically significant, although a trend for higher incidence in patients with longer follow-ups was identified $(\mathrm{p}=0.455)$. It is also noteworthy that two patients in the study group, who previously reported clinical signs of FS later confirmed vanishing of symptoms over time. We believe that this fact highlights the importance of regular and longer follow-ups, which may affect the incidence of this syndrome in an unpredictable way. 
The scale by Luna-Ortiz et al is commonly considered a useful tool to objectively evaluate the severity of FS. ${ }^{[1]}$ However, patient-reported findings, which may even have a greater value in management of this condition, should also be considered together with the findings of objective evaluations. To avoid overtreatment and related risks, the indication of treatment should be based on patientreported findings. To serve this purpose, such an effort was undertaken in this study and patients who did not report any symptoms postoperatively did not undergo any medical or surgical treatments.

Among the sequelae affecting patients' overall quality of life, lowest scores were attributed to FS, followed by depression of the parotid bed and dysesthesia around the ear lobe. The latter two complications were the most common in our study, although their impact on affected patients was not significant. Another commonly reported complication of parotidectomy is sensory deficits around the earlobe due to great auricular nerve sacrifice. ${ }^{[29]}$ As they are encountered more frequently following parotidectomy, overall scores of depression of the parotid bed and dysesthesia around the ear lobe were lower despite their higher minimum scores. Permanent facial nerve dysfunction was encountered in two patients who had malignant tumors and this finding was found to be in agreement with the previous literature. ${ }^{[30]}$ When these findings are interpreted together with findings of previous studies, it can be concluded that FS may be of greater significance among

\section{References}

1. Erkan SO, Tuhanioglu B, Erkan ZA, Güney Z, Taş ZA. Parotid mass: Toxoplasma lenfadenitis. ENTcase 2017;2:325.

2. Ford FR, Woodhall B. Phenomena due to misdirection of regenerating fibers of cranial, spinal and automatic nerves. Arch Surg 1938;38:480-96.

3. Gardner WJ, McCubbin JW. Auriculotemporal syndrome; gustatory sweating due to misdirection of regenerated nerve fibers. J Am Med Assoc 1956;160:272-7.

4. Laccourreye O, Muscatelo L, Naude C et al. Botulinum toxin type A for Frey's syndrome: a preliminary prospective study. Ann Otol Rhinol Laryngol 1998;107:52-5.

5. Rustemeyer J, Eufinger H, Bremerich A. The incidence of Frey's syndrome. J Craniomaxillofac Surg 2008;36:34-7.

6. Minor V. Ein neues Verfahren zu der klinischen Untersuchung der Schweißabsonderung. [Article in German] Deutsche Zeitschrift für Nervenheilkunde 1928;101:302-8.

7. Farrell ML, Kalnins IK. Frey's syndrome following parotid surgery. Aust N Z J Surg 1991;61:295-301.

8. Gordon AB, Fiddian RV. Frey's syndrome after parotid surgery. Am J Surg 1976;132:54-8. other complications of parotidectomy, which have a negative impact on quality of life, due to its frequency that is higher than other more severe complications.

Certain limitations of this study need to be taken into consideration, when interpreting its findings. Among these, limited follow-up periods and relatively small sample size in addition to others due to its retrospective nature can be considered a limitation to generalize its outcomes. However, the authors of this study believe that its findings, if validated by future research, may aid clinicians in better understanding the frequency of a common complication of parotid surgery, and also in identifying the need for further treatment. Furthermore, these findings may contribute to an effort to determine the cumulative incidence of Frey Syndrome, if incorporated with the findings from different centers.

\section{Conclusion}

FS is reported to be among the most debilitating sequelae after parotidectomy. To avoid overtreatment, true incidence of FS remains to be identified in study samples from different centers. By this means, clinicians can make more accurate definitions for indications of preventive procedures as well as treatment approaches. Patient-reported outcomes need to be taken into consideration in addition to findings of objective evaluations to effectively manage FS symptoms and also to avoid overtreatment.

9. LinderTE,HuberA, Schmid S. Frey's syndrome after parotidectomy: a retrospective and prospective analysis. Laryngoscope 1997;107:1496-501.

10. Xie S, Wang K, Xu T et al. Efficacy and safety of botulinum toxin type A for treatment of Frey's syndrome: evidence from 22 published articles. Cancer Med 2015;4:1639-50.

11. Luna-Ortiz K, Sansón-RíoFrío JA, Mosqueda-Taylor A. Frey syndrome. A proposal for evaluatin severity. Oral Oncol 2004;40:501-5

12. Laage-Hellman JE. Gustatory sweating and flushing after conservative parotidectomy. Acta Otolaryngol 1957;48:234-52.

13. LaccourreyeH,Laccourreye $\mathrm{O}$, Cauchois $\mathrm{R}$ et al. Total conservative parotidectomy for primary benign pleomorphic adenoma of the parotid gland: a 25-year experience with 229 patients. Laryngoscope 1994;104:1487-94.

14. Lafont M, Whyte A, Whyte J et al. Frey syndrome: factors influencing the time to event. Int J Oral Maxillofac Surg 2015;44:834-9.

15. Tuncel A, Karaman M, Sheidaei S et al. A comparison of incidence of Frey's syndrome diagnosed based on clinical signs and Minor's test after parotis surgery. Kulak Burun Bogaz Ihtis Derg 2012;22:200-6.

16. Dulguerov N, Makni A, Dulguerov P. The superficial musculoaponeurotic system flap in the prevention of Frey syndrome: A meta-analysis. Laryngoscope 2016;126:1581-4. 
17. Sharma R. Prevention of Frey syndrome with superficial temporal fascia interpositioning: a retrospective study. Int J Oral Maxillofac Surg 2014;43:413-7.

18. Nofal AA, Mohamed M. Sternocleidomastoid Muscle Flap after Parotidectomy. Int Arch Otorhinolaryngol 2015;19:319-24.

19. Xiao M, Shi L, LiuYS. [Effectiveness of acellular dermal matrix and parotid fascia in preventing Frey's syndrome: meta analysis]. Shanghai Kou Qiang Yi Xue 2014;23:628-33.

20. Hayashi A, Mochizuki M, Suda S, et al. Effectiveness of platysma muscle flap in preventing Frey syndrome and depressive deformities after parotidectomy. J Plast Reconstr Aesthet Surg 2016;69:663-72.

21. Grosheva M, Horstmann L,Volk GF, et al. Frey's syndrome after superficial parotidectomy: role of the sternocleidomastoid muscle flap: a prospective nonrandomized controlled trial. Am J Surg 2016;212:740-7.

22. Wille-Bischofberger A, Rajan GP, Linder TE et al. Impact of the SMAS on Frey's syndrome after parotid surgery: a prospective, long-term study. Plast Reconstr Surg 2007;120:1519-23.

23. Edward WH. Sternomastoid muscle flap for parotidectomy: the pros and cons. Br J Plast Surg 2002;55:88-9.

24. Ahmed OA, Kolhe PS. Prevention of Frey's syndrome and volume defi-cit after parotidectomy using the superficial temporal artery fascial flap. Br J Plast Surg 1999;52:256-60.
25. Cesteleyn L, Helman J, King S, et al. Temporoparietal fascia flaps and superficial musculoaponeurotic system plication in parotid surgery reduces Frey's syndrome. J Oral Maxillofac Surg 2002;60:1284-97.

26. Casani AP, Cerchiai N, Dallan I, et al. Benign tumours affecting the deep lobe of the parotid gland: how to select the optimal surgical approach. Acta Otorhinolaryngol Ital 2015;35:80-7.

27. Chulam TC, Noronha Francisco AL, Goncalves Filho J, et al. Warthin's tumour of the parotid gland: our experience. Acta Otorhinolaryngol Ital 2013;33:393-7.

28. Lee CC, Chan RC, ChanJY. Predictors for Frey Syndrome Development After Parotidectomy. Ann Plast Surg 2017;79:39-41.

29. Patel N, Har-El G, Rosenfeld R. Quality of life after great auricular nerve sacrifice during parotidectomy. Arch Otolaryngol Head Neck Surg 2001;127:884-8.

30. Mehle ME, Kraus DH, Wood BG, et al. Facial nerve morbidity following parotid surgery for benign disease: the Cleveland Clinic Foundation experience. Laryngoscope 1993;103:386-8.

This is an open access article distributed under the terms of the Creative Commons Attribution-NonCommercial-NoDerivs 3.0 Unported (CC BYNCND3.0) Licence (http://creativecommons.org/licenses/by-nc-nd/3.0/) which permits unrestricted noncommercial use, distribution, and reproduc- tion in any medium, provided the original work is properly cited.

Please cite this article as: Daloglu M, Guney K. The Incidence And Severity Of Frey's Syndrome After Parotidectomy: A Retrospective Study. ENT Updates 2019;9(2): 74-80 